
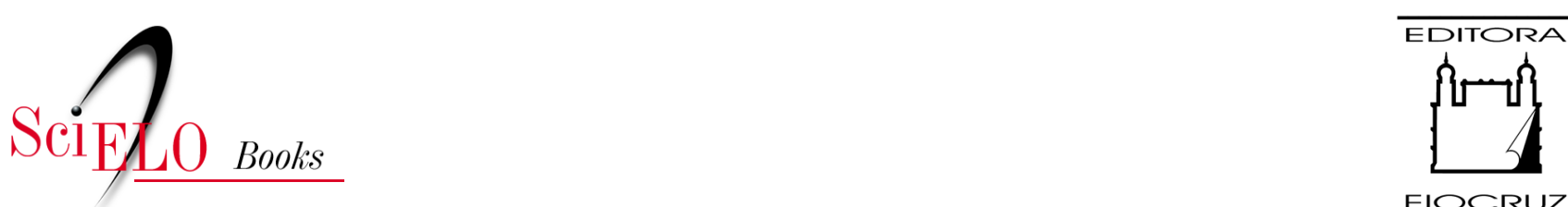

FIOCRUZ

\title{
Clássicos \& Comentários 5 - Émile Brumpt - O xenodiagnóstico: aplicação ao diagnóstico de algumas infecções parasitárias e em particular a tripanossomose de Chagas
}

\author{
José da Rocha Carvalheiro \\ Nara Azevedo \\ Tania C. de Araújo-Jorge \\ Joseli Lannes-Vieira \\ Maria de Nazaré Correia Soeiro \\ Lisabel Klein \\ (orgs.)
}

\section{SciELO Books / SciELO Livros / SciELO Libros}

CARVALHEIRO, J. R., AZEVEDO, N., ARAÚJO-JORGE, T. C., LANNES-VIEIRA, J., SOEIRO, M. N. C., and KLEIN, L., eds. Émile Brumpt - O xenodiagnóstico: aplicação ao diagnóstico de algumas infecções parasitárias e em particular a tripanossomose de Chagas. In: Clássicos em Doença de Chagas: histórias e perspectivas no centenário da descoberta [online]. Rio de Janeiro: Editora FIOCRUZ, 2009, pp. 187-204. ISBN: 978-65-5708-101-3.

https://doi.org/10.7476/9786557081013.0010.

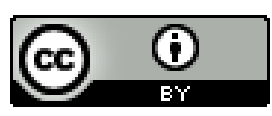

All the contents of this work, except where otherwise noted, is licensed under a Creative Commons Attribution $\underline{4.0 \text { International license. }}$

Todo o conteúdo deste trabalho, exceto quando houver ressalva, é publicado sob a licença Creative Commons Atribição 4.0.

Todo el contenido de esta obra, excepto donde se indique lo contrario, está bajo licencia de la licencia $\underline{\text { Creative }}$ Commons Reconocimento 4.0. 


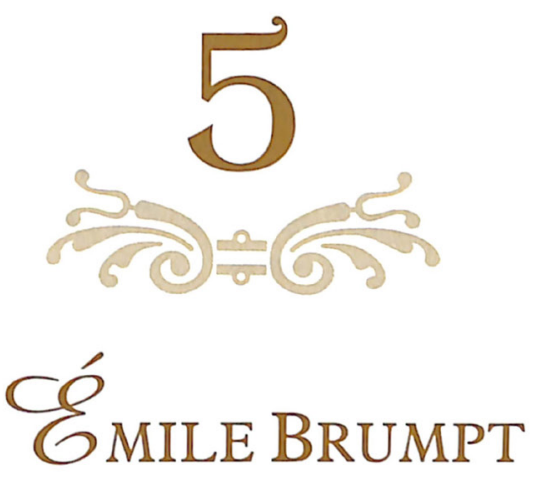

O xenodiagnóstico: aplicação ao diagnóstico de algumas infecções parasitárias e em particular a tripanossomose de Chagas.

Anais Paulistas de Medicina e Cirurgia, 3(5): 97-102, 1914. 


\section{Émile Brumpt (1877-1951)}

Parasitologista francês, descobriu o parasito responsável pela malária aviária, Plasmodium gallinaceum. Desenvolveu a técnica do xenodiagnóstico para as doenças parasitárias e realizou estudos importantes sobre malária, doença de Chagas, doença do sono, leishmanioses, oncocercose e esquistossomose urinária. 


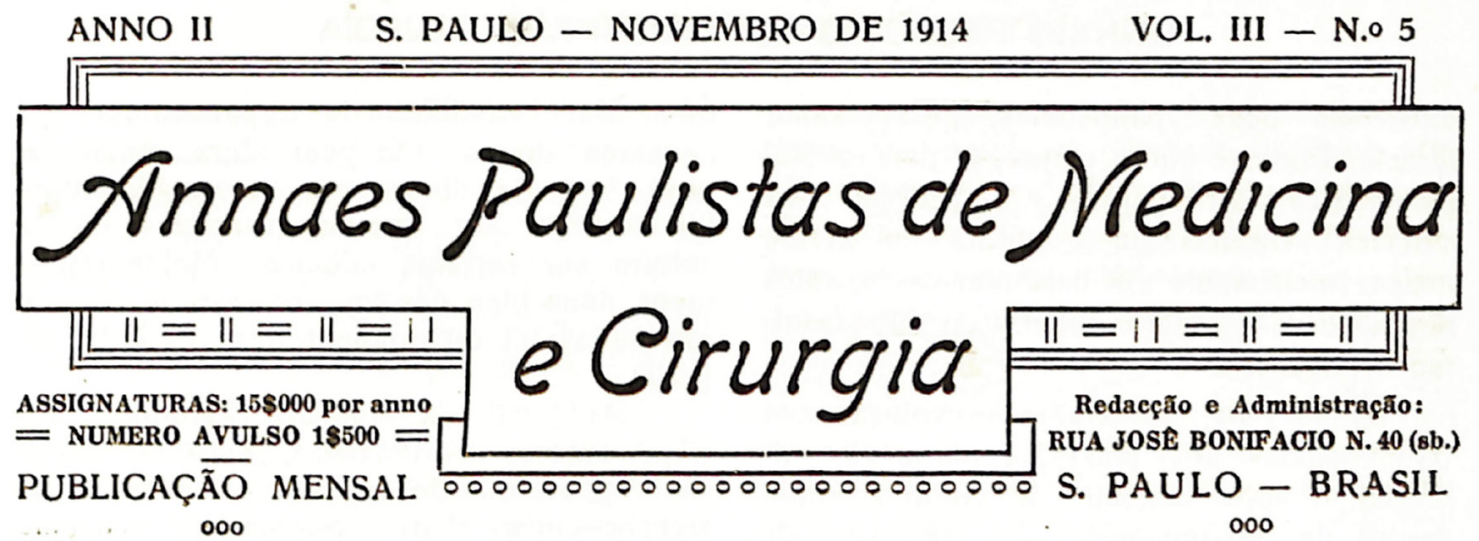

\section{O XENODIAGNOSTICO}

APPLICAÇĀO AO DIAGNOSTICO DE ALGUMAS INFECÇŌES PARASITARIAS E EM PARTICULAR Á TRYPANOSOMOSE DE CHAGAS POR

E. BRUMPT

Professor de Parasitologia da Faculdade de Medicina de Sâo Paulo

(Trabalho do Laboratorio de Parasitologia da mesma Faculdade)

\section{LE XENODIAGNOSTIC}

APPLICATION AU DIAGNOSTIC DE QUELQUES INFECTIONS

PARASITAIRES ET EN PARTICULIER Á LA TRYPANASOMOSE CHAGAS PAR

E. BRUMPT

Profoesour de Parasitologio de la Faculté de Médicine de São Paulo

(Travail du Laboratoiro de Parasitologio de la même Faculté)

Dou o nome de Xenodiagnostico (de $\xi \varepsilon v o s$, hospede) ao diagnostico que proponho fazer por meio do hospede, agente vector da molestia parasitaria, ou, por meio de um hospede vicariante que possa garantir a cultura e evolução do parasita. E' em summa uma cultura natural do parasita nos hospedes favoraveis.

O diagnostico das molestias parasitarias do sangue é ás vezes muito delicado. Nas trypanosomoses em particular, não só no homem como nos animaes os mais diversos, sabe-se como é difficil por vezes verificar a
Je donne le nom de Xenodiagnostic (de Gॄvos, hôte) au diagnostic que je propose de faire au moyen de l'hôte agent vecteur habituel de la maladie parasitaire, ou, à l'aide d'un hôte vicariant pouvant assurer la culture et l'évolution du parasite. C'est en somme une culture naturelle du parasite chez des hôtes favorables.

Le diagnostic des maladies parasitaires du sang est parfois très délicat. Dans les trypanosomoses en particulier, aussi bien chez l'homme que chez les animaux les plus divers, on sait combien il est parfois difficile 


\section{ANNAES PAULISTAS DE MEDICINA E CIRURGIA}

existencia dos trypanosomas, pelo exame directo. Pode-se então empregar para o diagnostico a centrifugação, a inoculação nos animaes sensiveis ou a cultura em certos meios. Infelizmente em bastantes casos, estes meios se não podem utilisar ou dão resultados negativos.

Desde 1904, ao estudar a evolução dos trypanosomas dos peixes, chamou-me attenção o apparecimento de culturas abundantes de trypanosomas no estomago de sanguesugas novas que sugaram peixes indemnes, pelo exame directo, de trypanosomas ou tendo mostrado sómente trypanoplasmas.

Tive occasião, bem a miudo, depois dáquella epocha, de verificar factos semelhantes. Appliquei este processo de diagnostico pelas sanguesugas novas (1) ao estudo dos trypanosomas dos batrachios e das serpentes do Brasil.

As sanguesugas estudadas no Brasil pertenciam a duas especies. A primeira é uma especie brasileira, Placobdella brasiliensis Brumpt, 1914 - commum nas rans do Brasil e hospede transmissor do Trypanosoma leptodactyli, Carini - como pude demonstrar. (2) No decurso de trabalhos feitos no Instituto de Vital Brasil, de Butantan, appliquei o xenodiagnostico ao estudo dos trypanosomas das serpentes.

Consegui primeiramente demonstrar que os trypanosomas - Trypanosoma Brasili, Brumpt, 1914 - d'uma serpente aquatica -

(1) Utilisam-se estas sanguesugas ou logo depois de nascidas, quando fique provado que nunca apresentem infecçâo hereditaria ou depois de varios repastos em animaes não infestados. Este ultimo processo permitte terem-se sanguesugas mais edosas e volumosas, que sugam maior quantidade de sangue.

(2) O Trypanosoma leptodactyli de Carini é a forma joven dum grande trypanosoma do Leptodactylus ocellatus. Não tenho terminada a memoria com figuras que devo publicar sobre sua cvoluçâo. Resumo no entanto sua historia dizendo que a fotma sanguicola se apresenta em bola, perde seu flagello e se divide primeiramente em dois no estomago da sanguesuga; em seguida, depois de uma evolução normal dá Trypanosomas metacyclicos que passam para a bainha da tromba e são inoculados ás rans. de déceler l'existence de trypanosomes par l'examen direct. On peut alors employer, pour faire le diagnostic, la centrifugation, l'inoculation aux animaux sensibles ou la culture sur certains milieux. Malheureusement, dans bien des cas, ces moyens ne sont pas utilisables ou donnent des résultats négatifs.

Dès 1904, en étudiant l'évolution des trypanosomes des Poissons, j'avais été frappé de l'apparition de cultures abondantes de trypanosomes dans l'estomac de sangsues neuves ayant sucé des Poissons indemnes de Trypanosomes à l'examen direct, ou, ayant montré seulement des Trypanoplasmes.

J'ai eu bien souvent l'occasion, depuis cette époque, de verifier des faits semblables. J'ai appliqué ce procedé de diagnostic, par les sangsues neuves (1), á l'étude des trypanosomes des Batraciens et des serpents du Brésil.

Les sangsues étudiées au Brésil appartenaient à deux espèces. La première est une espèce brésilienne - la Placobdella brasiliensis - Brumpt 1914, commune sur les Grenouilles du Brésil et hôte transmetteur du Trypanosoma leptodactyli, Carini-, ainsi que j'ai pu le démontrer (2). La seconde est la Placobdella catenigera de la France Meridionale dont je poursuis l'élevage de puis 1906.

En faisant piquer des Grenouilles considerées comme non infectées aprés un ou plusieurs examens négatifs par des sangsues neuves, j'ai eu des cultures abondantes chez ces dernières. Le fait est facile á expliquer

(1) Les sangsues sont utilisées soit dès leur naissance, quand il est démontré qu'elles ne présentent jamais d'infection héréditaire, soit après plusieurs repas sur des animaux non infectés. Ce dernier procédé permet d'avoir des sangsues agées plus volumineuses et suçant une plus grande quantité de sang.

(2) Le Trypanosoma leptodactyli de Carini est la forme jeune d'un grand Trypanosome du Leptodactylus ocellatus. Le mémoire avec figures que je dois publier sur son évolution n'est pas terminé. Je résume son histoire en disant que la forme sanguicole se met en boulet perd son flagelle et se divise d'abord en deux dans l'estomac de la sangsue, puis aprés une évolution normale donne des Trypanosomas metacycliques. Ceux-ci passent dans la gaine de la trompe et sont inoculés aux Grenouilles. 


\section{ANNAES PAULISTAS DE MEDICINA E CIRURGIA}

Helicops modestus - evoluiam facilmente e rapidamente na Placobdella brasiliensis.

Contava eu dar uma descripção completa da Placobdella brasiliensis, n. sp., na memoria que esperava publicar sobre a evolução do Trypanosoma leptodactyli, porém minha brusca partida para a guerra francoalleman fez fracassar meus projectos. Contento-me pois em dizer que esta sanguesuga, de côr verde azeitona carregada, apresenta pequenas manchas amarellas, pode attingir a 6 centimetros de comprimento e apresenta uma consistencia molle como a Hemiclepsis tesselata, nadando bem e podendo ir á cata de sua presa. A criação délla é facil; obtive, com um pouco de paciencia, milhares de exemplares que me serviram e me hão de servir para numerosas experiencias.

- Esta sanguesuga alimenta-se facilmente de rans de diversas especies, de crocodilos, serpentes, tartarıgas, mas recusa picar certos sapos e peixes. Ao cabo do sexto repasto o animal torna-se adulto; na copula, os animaes applicam-se um ao outro, spermatophoros; a fecundação effectua-se, como habitualmente, pela via hypodermica. A postura se faz sob o ventre; os ovos amarellos, contidos em casulos hyalinos, apegam-se uns aos outros.

Um animal pode pôr, conforme o set tamanho, de trinta a cem e mais ovos.

O Trypanosoma Brasili muito se parece com o Trypanosoma leptodactyli adulto; evolue rapidamente no estomago da Placobdella brasiliensis e dá, em algumas semanas, formas metacyclicas extremamente numerosas. Estas formas metacyclicas não passam para a bainha da tromba, mesmo depois de varios mezes, e é provavel que a serpente se infeste ingerindo as sanguesugas parasitadas.

A evolução deste Trypanosoma se faz tambem na Placobdella catenigira.

Ao estudar a evolução, na Placobdella brasiliensis, d'uma Hemogregarina de outra serpente - Radinia Merremii - surprehendeu-me achar em abundancia, no estomago das sauguesugas, flagellados e finalmente Trypanosomas metacyclicos. par l'excellence de l'hôte transmetteur chez lequel l'évolution se fait dans 100 pour cent des cas et d'autre part par la quantité de sang ingérée qui est de 10 a 500 fois plus grande que la goutte de sang susceptible d'etre examinée au microscope.

Au cours des travaux faits à l'Institut de Vital Brasil à Butantan (São Paulo) j'ai appliqué ce Xenodiagnostic à l'ètude des Trypanosomes des Serpents. J'ai d'abord pu démontrer que les trypanosomes, Trypanosoma Brasili, Brumpt 1914 - d'un serpent aquatique l'Helicops modestus évoluait facilement et rapidement chez la Placobdella brasiliensis.

J'espérais donner une description complète de la Placobdella brasiliensis n. sp. dans le mémoire que je comptais publier sur l'évolution du Trypanosoma leptodactyli; mon brusque départ pour la guerre franco-allemande a changé mes projets. - Je me contente de dire que cette sangsue de couleur vert olive foncé présente de petites taches jaunes; elle peut atteindre 6 centimètres de longueur et présente une consistance molle comme l'Hemiclepsis tesselata, elle nage bien et peut aller à la recherche de sa proie. L'élevage en est facile; avec un peu de patience, j'en ai obtenu des milliers d'exemplaires qui m'ont servi et serviront pour de nombreuses expériences.

Cette sangsue se nourrit facilement sur des Grenouilles d'especès diverses, sur les Crocodiles, Serpents, Tortues, mais refuse de piquer certains Crapauds et les Poissons.

Au bout du sixiemè repas l'animal devient adulte; en s'accouplant les animaux deposent des spermatophores; la fécondation est comme d'habitude, effectué par la voie hypodermique. La ponte s'effectue sous le ventre; les œufs jaunes contenus dans des cocons hyalins sont accolés les uns aux autres. Un animal peut pondre, suivant sa taille, de trente à cent et quelques œufs.

Le Trypanosoma Brasili, ressemble beaucoup au Trypanosoma leptodactyli adulte; il évolue rapidement dans l'stomac de la Placobdella brasiliensis et donne, en quelques semaines, des formes métacycliques extrémement nombreuses. Ces formes métacycliques ne passent pas dans la gaine de la trompe, même après plusieurs mois, et il est probable que le serpent s'infecte en engérant les sangsues parasitées. L'evolution de ce Trypanosomes s'effectue aussi chez Placobdella catenigera.

En étudiant l'évolution, chez Placobdella brasiliensis, d'une Hémogregarine d'un autre serpent vivant volontiers dans l'eau, le Radinia Merrimii, j'ai été surpris de trouver en 


\section{ANNAES PAULISTAS DE MEDICINA E CIRURGIA}

Foi sómente em um quinto exame a fresco que pude encontrar no sangue da serpente o Trypanosoma cuja existencia me era assignalada pelo Xenodiagnostico.

O Trypanosoma de Radinia Merremii parece-se muito com o Trypanosoma Brasili. A falta de animaes novos impedio-me de estabelecer a identidade e differenciação delles.

Em uma cobaya infestada com o Trypanosoma Cruzi (virus da Bahia), e năo tendo Trypanosomas pelo exame directo, a existencia do parasita poude ser demonstrada, fazendo picar este animal por larvas, no terceiro estadio, do Triatoma (Conorhinus) megista.

Fazendo nymphas de $T$. megista picar tres crianças atacadas da molestia de Chagas, antiga, só tive resultados negativos, identicos aliás aos obtidos por outros meios de diagnostico.

Em casos recentes da Molestia de Chagas a infecção certamente se faria. Os Triatomas são capazes, com effeito, de garantir em qualquer edade, a.cultura do Trypanosoma Cruzi, e, como podem absorver de 10 a 500 vezes mais sangue que a quantidade que se pode pôr entre lamina e laminula, apresentam elles vantagens consideraveis sobre $\mathbf{o}$ exame directo.

Os triatomas são mais vantajosos que as Cobayas cujos leucocytos podem destruir alguns raros Trypanosomas inoculados com o sangue de um doente.

Para o diagnostico da molestia de Chagas, pois, julgo ser conveniente tentar o Xenodiagnostico com larvas ou nymphas de Triatomas, todas as vezes que os outros meios não sejam applicaveis ou se mostrem negativos.

A criação dos Triätomas necessarios para o Xenodiagnostico da molestia de Chagas é das mais simples.

Partindo de ovos, obtem-se larvas indemnes de parasitas, as quaes podem ser alimentadas em animaes sãos ou refractarios á infecção pelo Trypanosoma Cruzi, como gallinhas e pombos. abondance dans l'estomac des sangsues des flagelles et facilement des Trypanosomes métacycliques. C'est seulement à un cinquième examen à frais que j'ai pu trouver dans le sang du serpent le Trypanosome dont l'existence m'était signalée par le Xenodiagnostic.

Le Trypanosome de Radinia Merremii ressemble beaucoup au Trypanosoma Brasili. Le manque d'animaux neufs m'a empêché d'établir leur identité ou de les différencier.

Chez un Cobaye infecté avec le Trypanosoma Cruzi (virus de Bahia) et n'ayant pas de Trypanosomes à l'examen direcct, l'existance de parasite a pu être démontrée en faisant piquer cet animal par des larves au troisiéme stade de Triatoma (Conorhinus) megista.

En faisant piquer trois enfants atteints de maladie de Chagas ancienne par des nymphes de Triatoma megista, je n'ai obtenu que des résultats négatifs, ainsi d'ailleurs que ceux obtenus par les autres moyens de diagnostic. Dans des cas de maladie de Chagas, recents, il est certain que l'infection se serait produite. Les Triatomes sont en effet capables d'assurer la culture du Trypanosoma Cruzi à tout âge, et, comme ils peuvent absorber de 10 a 500 fois plus de sang qu'il n'est possible d'en mettre entre lame et lamelle ils présentent un avantage considérabie sur l'examen direct. Les Triatomes sont également plus avantageux que les Cobayes dont les leucocytes peuvent détruire les quelques rares Trypanosomies inoculés avec le sang d'un malade.

Donc pour le diagnostic de la maladie de Chagas, je crois qu'il est bon de tenter le Xenodiagnostic avec des larves ou des nymphes de Triatomes, chaque fois que les autres moyens ne sont pas applicables ou seront négatifs.

L'élevage des Triatomes nécessaires pour le Xenodiagnostic de la maladie de Chagas est des plus simples. En partant de œuf, l'on obtient des larves indemmes de parasites que l'on peut nourrir sur des animaux sains ou réfractaires à l'infection par le Trypanosoma Cruzi, comme les Poules et les Pigeons. 


\section{ANNAES PAULISTAS DE MEDICINA E CIRURGIA}

Nas experiencias de infestação que fiz com diversas especies de Triatomas $(T$. infestans, $T$. megista) ou de Rhodnius ( $R$. prolixus) obtive sempre resultados positivos de cento por cento. Esta porcentagem distingue estes maravilhosos hospedes vectores das Glossinas que, na molestia do somno e em outras trypanosomoses animaes se infestam em proporção minima.

Creio que o Xenodiagnostico, no estudo systematico e geographico da molestia de Chagas no homem e nos animaes domesticos ou selvagens do Brasil, poderá prestar os maiores serviços.

De facto, nas regiões do interior do Brasil habitadas, por gente muito hospitaleira mas pouco familiarisada com os processos medicos, é difficil, no decurso de um inquerito, fazer frottis de sangue pela picada dos dedos das crianças. Estes frottis são além disso inutilisaveis geralmente pela raridade e fragilidade do Trypanosoma Cruzi. O exame directo do sangue com o microscopio é difficil, pois que o iransporte d'um microscopio, a cavallo, apresenta muitos inconvenientes e o exame entre lamina e laminula faz perder um tempo precioso.

Melhor e mais facil em theoria seria tirar alguns centimetros cubicos de sangue ao doente e inoculal-o a uma cobaya. Esta puncção, porém, seria bem raramente acceita, e, poderia, pela falta de assistencia local util, apresentar perigos grandes no correr de uma expedição.

E' en face d'estas difficuldades de ordem material que proponho o emprego anodino do Xenodiagnostico.

Todos os doentes conhecem os Triatomas e podem consentir a se deixarem picar por estes insectos cuja picada é indolor. As larvas no terceiro estadio e as nymphas de Triatoma e de Rhodnius sugam muito sangue.

Uma nympha de $T$. megista pesa em jejum 0 , gr 130; bem cheia pesa uma gramma, sugando pois $0 \mathrm{gr}, 870$ mais ou menos. Uma nympha de $T$. infestans em jejum pesa $0 \mathrm{~g}, 065$ approximadamente; cheia, pesa $0 \mathrm{~g}, 50$ e suga
Dans les expériences d'infestation que j'ai faites avec diverses espèces de Triatomes (T. infestans, T. megista) ou de Rhodnius (R prolixus) j'ai toujours obtenu 100 pour 100 de succès; ce pourcentage distingue ces merveilleux hôtes vecteurs des Glossines qui, dans la maladie du sommeil et autres Trypanosomoses s'infectent dans une proportion minime.

Pour faire une étude systématique et géographique de la maladie de Chagas chez l'Homme ou chez les animaux domestiques ou sauvages du Brésil, je crois que le Xenodiagnostic rendra les plus grands services.

En effet, dans la région de l'intérieur du Brésil où habitent des gens très hospitaliers mais peu familiarisés avec les pratiques médicales, il est déjà difficile, au cours d'une enquëte de faire des frottis de sang en piquant les doigts des enfants. D'ailleurs ces frottis de sang sont généralement inutilisables par suite de la rareté et de la fragilité des Trypanosoma Cruzi.

L'examen direct du sang avec le microscope est difficile, car le transport d'un microscope sur la selle d'un mulet présente des inconvénients de toutes sortes et l'examen entier d'une lamelle fait perdre un temps précieux.

Il serait meilleur et plus facile, théoriquement, de prélever quelques centimètres cubes de sang au malade et d'inoculer un cobaye. Mais cette ponction ne serait acceptêe que trés rarement et, étant donné le manque d'assistance utile, pourrait présenter de gros dan. gers au cours d'une expédition.

C'est en présence de ces difficultés d'ordre matériel que je propose l'emploi anodin du Xénodiagnostic.

Tous les malades connaissent les Triatomes et peuvent consentir á se laisser faire une ponction de sang naturelle par ces insectes dont la piqûre est indolore.

Les larves au 3 e stade et les nymphes de Triatoma et de Rhodnitus sucent beaucoup de sang. A jeun, une nymphe de $T$. megista pèse $0, g 130$; bien gorgée, elle pèse 1 gramme et suce donc environ $0, g 870$ de sang. 


\section{ANNAES PAULISTAS DE MEDICINA E CIRURGIA}

por conseguinte $0 \mathrm{~g}, 435$ mais ou menos. A sucção dura no homem de $1 / 4$ a $1 / 2$ hora e é facil alias, para se ganhar tempo, fazer picar ao mesmo tempo varias pessoas ou animaes suspeitos de uma mesma habitação.

As Triatomas repletas de sangue são postas em seguida dentro de tubos separados e rotulados, e collocados, de volta da expedição, na estufa a $30.0^{\circ}$ onde o desenvolvimento dos Trypanosomas se effectua rapidamente.

Alimentando-se depois estes insectos e examinando-se as suas dejecções, ou então dissecando-os pode-se facilmente verificar os infestados e os indemnes.

Assim é que se pode fazer o Xenodiagnostico, novo meio de investigação destinado a prestar grandes serviços toda a vez que o hospede vector d'uma molestia parasitaria do homem ou dos animaes seja de facil criação em estado pureza e absorva uma bôa quantidade de sangue.

S. Paulo, 2 de Agosto, 1914
Une nymphe à jeun de $T$. infestans pesè environ $0, g 065$, gorgée, elle pèse $0, g 50$ et suce par consequent environ $0, \mathrm{~g} 435$ de sang.

La durée de la succion sur l'Homme est d'environ $1 / 4$ d'heure à $1 / 2$ heure, il est d'ailleurs facile, pour gagner du temps, de fa re piquer simultanément plusieurs personnes ou animaux suspects d'une même habitation.

Les Triatomes gorgées de sang sont ensuite mises dans des tubes à part, étiquetés, et au retour de l'expedition mis à l'étuve a $30^{\circ}$ où le dévéloppement des Trypanosomes s'effectue rapidement. En nourissant ensuite ces insectes et en examinant leurs déjections, ou bien en les dissequant on peut facilement determiner ceux qui sont infectés et ceux qui sont indemnes, c'est ainsi que peut se faire le Xenodiagnostic, moyen nouveau d'investigation appelé à rendre de ơrands services quand l'hôte vecteur d'une maladie parasitaire de l'Homme ou des animaux est facile a élever à l'ètat de pureté et absorbe une bonne quantité de sang.

São Paulo, 2 Août 1914.

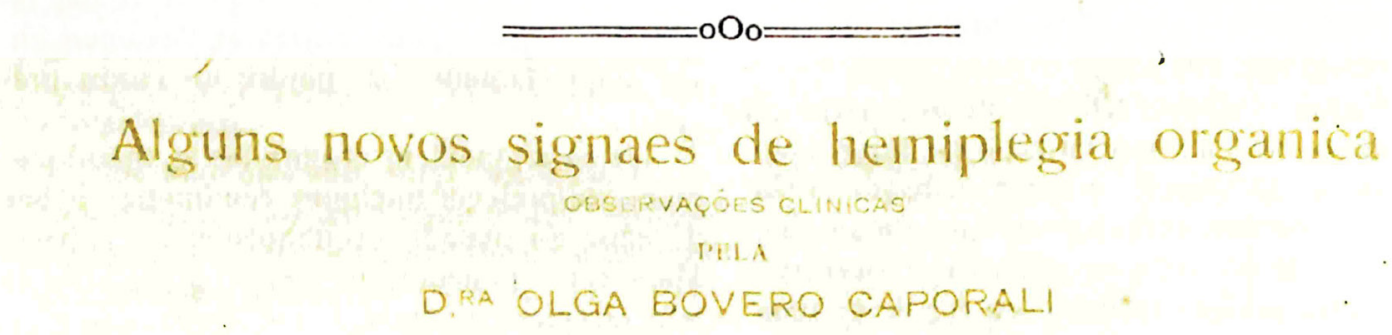

Ln 1807 Bathinsli (1) descreven, com o mone de sfexaro combinada la eoxat e do mafur., mon phenomeno que frequentewente sceocontra na hemiptegiat organica, a yme

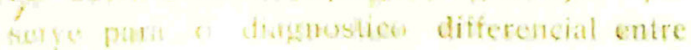
estu homplemato a hemplegia hysteriea.

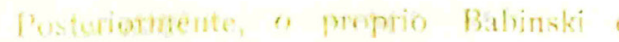

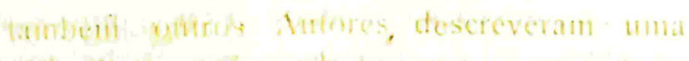

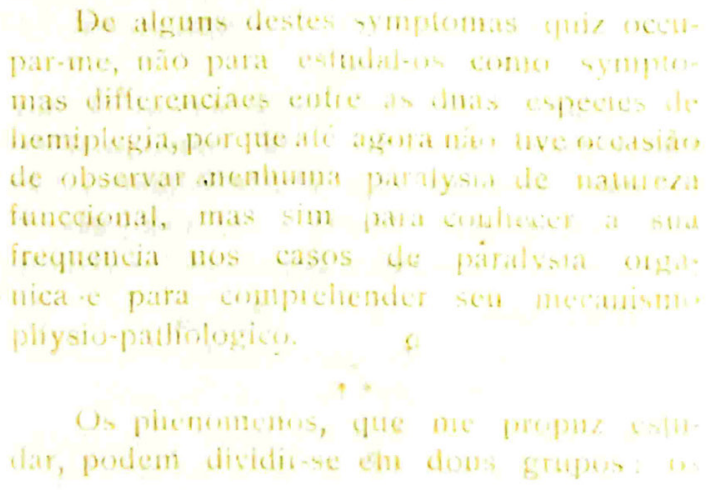

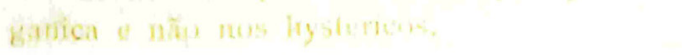
000102000 


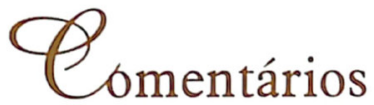

\title{
95 Anos da História do Xenodiagnóstico e sua Contribuição para o Diagnóstico Etiológico da Doença de Chagas
}

\author{
Constança Carvalho Britto \\ Laboratório de Biologia Molecular e Doenças Endêmicas \\ Instituto Oswaldo Cruz/Fiocruz \\ Marli Maria Lima \\ Laboratório de Ecoepidemiologia da Doença de Chagas \\ Instituto Oswaldo Cruz/Fiocruz
}

No ano de 1914, quando Brumpt introduz o método de Xenodiagnóstico (XD) e demonstra seu potencial de aplicação ao diagnóstico parasitológico da doença de Chagas, a tripanossomíase americana já exigia atenção das autoridades sanitárias brasileiras, tendo em vista as limitações existentes na época em se diagnosticar doenças parasitárias do sangue pelos métodos parasitológicos disponíveis. Em seu trabalho, Brumpt comenta a dificuldade em demonstrar a presença de tripanossomos diretamente no sangue humano ou de animais por meio da microscopia de sangue a fresco, que gerava resultados negativos com freqüência; ou, alternativamente, pelos procedimentos de inoculação em animais suscetíveis ou cultivo in vitro, os quais, por sua vez, eram pouco utilizados por constituírem métodos laboriosos. A observação direta ao microscópio, além de pouco sensível, reunia problemas logísticos críticos para sua execução, especialmente quando envolvia expedições em áreas interioranas do Brasil. Brumpt ressalta os inconvenientes de transportar um microscópio na sela de um cavalo durante uma expedição, além do tempo gasto para a leitura de uma lâmina.

O método proposto por Brumpt (1914) consistia em verificar se os hospedeiros invertebrados que atuam como vetores habituais da doença de Chagas, criados em laboratório e livres de infecção, se encontravam infectados após sugarem o sangue de um suposto portador da infecção pelo Trypanosoma cruzi; isto é, o método propiciava o cultivo natural do parasito no seu hospedeiro favorável. Nesse contexto, por que não dizer que o XD foi uma inovação em 'biotecnologia' no início do século XX? De fato, a proposta de Brumpt visava a uma aproximação ao processo natural de transmissão da doença de Chagas, ou seja, triatomíneos vetores eram postos para se alimentar do sangue de paciente suspeito, e o parasito (caso 
presente no sangue do paciente), no ato do repasto sangüíneo de seu hospedeiro natural, ia ao encontro do ambiente favorável a seu ciclo de vida; esta seria a grande vantagem do método, por garantir a multiplicação e evolução do T. cruzi no seu hospedeiro vetor. Certamente, a demonstração indireta da presença do T. cruzi em sangue pelo emprego do XD contribuiu de forma significativa para o melhoramento do diagnóstico etiológico da doença de Chagas, principalmente devido à maior sensibilidade do método decorrente do processo natural de ampliação in vivo do parasito no inseto vetor.

Os primeiros relatos do sucesso da aplicação do XD foram observados ainda em 1904, quando Brumpt estudava a evolução dos tripanossomos de peixes e constatou, após um ou vários exames negativos por microscopia de sangue a fresco, o aparecimento de culturas abundantes de parasitos no tubo digestivo de sanguessugas jovens que haviam se alimentado do sangue de peixes considerados livres de infecção. Posteriormente, ele confirma esses achados com a aplicação de sanguessugas no estudo dos tripanossomos de rãs e serpentes do Brasil.

Em relação à doença de Chagas, a primeira aplicação do método foi feita com cobaia infectada com o "vírus da Bahia" (assim ele descreve a cepa de T. cruzi inoculada), deixandose 'picar' o animal por ninfas de terceiro estádio de Triatoma (Conorhinus) megista, triatomíneo mais tarde classificado como Panstrongylus megistus. Mais uma vez Brumpt ressalta a vantagem do XD em relação aos exames diretos a fresco, que apresentaram resultados negativos de encontro do parasito no sangue da cobaia. No entanto, ao aplicar o método em crianças "atacadas da moléstia de Chagas antiga", o autor só obteve resultados negativos, os quais também foram demonstrados pelos outros meios de diagnóstico. Pressupõe-se que essas crianças estariam na fase crônica da infecção, caracterizada pela parasitemia baixa e transitória, e o próprio autor afirma da certeza de poder evidenciar a infecção nas ninfas de T. megista, em se tratando da doença de Chagas recente (fase aguda).

Em seu artigo, Brumpt afirma que os triatomíneos eram capazes de garantir em qualquer "idade" a cultura de T. cruzi e que, pelo fato de poderem absorver de dez a quinhentas vezes mais sangue que a quantidade aplicada entre lâmina e lamínula, esses insetos apresentariam vantagem considerável sobre o exame microscópico direto. Da mesma forma, comenta sobre o benefício de se usar triatomíneos em relação à inoculação em cobaias, cujos leucócitos poderiam destruir alguns raros tripanossomas inoculados com o sangue de um doente. Em seus experimentos, diversas espécies de triatomíneos (Triatoma infestans, T. megista), além do Rhodnius prolixus, foram testadas, obtendo-se sempre 100\% de sucesso. Essa grande suscetibilidade dos triatomíneos ao desenvolvimento do T. cruzi fez com que Brumpt os qualificasse de "maravilhosos hospedeiros vetores".

Brumpt descreve a simplicidade de se criar triatomíneos isentos de infecção por flagelados e sugere a aplicação do XD utilizando-se ninfas de terceiro estádio (que sugam uma boa quantidade de sangue) aos estudos sistemáticos e geográficos da doença de Chagas no Brasil, que se propunham a investigar a presença do T. cruzi no homem ou em animais domésticos ou silvestres. $\mathrm{O}$ autor relata que os habitantes de regiões interioranas do Brasil eram pouco familiarizados com práticas médicas e que, muitas vezes, durante um inquérito epidemiológico, tornava-se difícil obter uma gota de sangue dos dedos das crianças, além do fato de esse material em geral não poder ser utilizado devido à raridade e fragilidade do parasito. Brumpt argumenta que os doentes nas localidades do interior do país conheciam os Triatomas e poderiam consentir em se deixarem 'picar' por esses insetos, cuja picada era indolor.

Segundo Brumpt, a sucção no homem teria duração aproximada de 15 a 30 minutos, e para se ganhar tempo o método poderia ser aplicado, em uma mesma habitação, simultaneamente 
em várias pessoas ou animais suspeitos. Em seguida, os triatomíneos repletos de sangue eram colocados separadamente dentro de tubos e rotulados. De volta das expedições, os insetos eram mantidos em estufa a $30^{\circ} \mathrm{C}$ para o rápido desenvolvimento dos tripanossomos. Em seu artigo, Brumpt não menciona por quanto tempo os insetos eram mantidos em estufa até o momento da investigação parasitológica para a presença do T. cruzi. No laboratório, os insetos eram alimentados em animais normalmente refratários ao parasito (pombos, galinhas) e a pesquisa do T. cruzi era feita por meio do exame das dejeções a fresco, ou após dissecção dos triatomíneos pelo exame do conteúdo intestinal.

A partir dos anos 30 do século XX, a introdução de uma série de procedimentos, abordando distintos aspectos, constituiu valiosa contribuição para favorecer o procedimento do XD: (i) escolha da espécie de triatomíneo, sendo recomendado o uso de uma espécie local, ou seja, o transmissor natural mais importante da doença na região estudada (Dias, 1940); (ii) definição do estádio das ninfas e do número de insetos por prova; (iii) definição do número de repetições do teste e duração de sua aplicação. Segundo Schenone (1999), as informações disponíveis não permitiam estabelecer um critério uniforme para essas questões. $\mathrm{Na}$ maioria das vezes os resultados não foram satisfatórios em casos suspeitos da doença de Chagas, particularmente nas infecções crônicas. Diante dessa situação, foi sugerida a realização de exames seriados de XD (Dias, 1940), semelhantes às técnicas empregadas em outras infecções parasitárias, o que contribuiu de forma significativa para o aumento da positividade do exame parasitológico nos pacientes crônicos (Castro, Alves \& Macedo, 1983; Coura et al., 1991). Outra recomendação referia-se ao exame rotineiro dos triatomíneos 30, 60 e 90 dias após a aplicação do método. A aplicação do XD pelo emprego simultâneo de quarenta ninfas de triatomíneos distribuídas em quatro dispositivos contendo grupos de dez insetos cada revelou ser um procedimento com bom desempenho para a avaliação da parasitemia na doença crônica (Borges-Pereira et al., 1989, 1996; Coura et al., 1991). Bronfen e colaboradores (1989) relataram um aumento da sensibilidade do XD após semeadura do conteúdo intestinal das ninfas de triatomíneos em meio LIT modificado, dando a esse procedimento o nome de xenocultura (a técnica facilitou o isolamento de cepas de T. cruzi).

O método inicialmente descrito referia-se ao XD clássico (natural), em que os triatomíneos em contato direto com a pele do paciente podiam causar irritação local com surgimento de máculas ou pápulas pruriginosas e, mais raramente, choque anafilático. Ainda na década de 40, uma solução para evitar as reações alérgicas decorrentes das picadas dos triatomíneos foi a introdução, por Romaña e Gil (1947), do XD artificial. Todavia, esse ensaio in vitro não foi usado na rotina durante anos, provavelmente por falta de uma membrana apropriada e de um anticoagulante adequado, o que dificultou seu emprego mais sistemático (Pineda, Luquetti \& Castro, 1998). Somente nas últimas décadas o método artificial despertou interesse, principalmente devido aos casos de reativação da doença de Chagas em cardiopatas transplantados e em imunossuprimidos, sobretudo aidéticos (Souza et al., 1988). Estudos visando à comparação dos dois métodos in vivo e in vitro apresentaram resultados similares (Freitas et al., 1955; Pineda, Luquetti \& Castro, 1998). Além disso, o XD artificial apresenta as vantagens de ser mais confortável para o paciente, eliminar eventuais reações alérgicas e permitir repetições do exame com maior facilidade. Atualmente, devido a questões éticas, o método de escolha tem sido o XD artificial, o qual consiste na coleta de $10 \mathrm{ml}$ de sangue que são então colocados em uma bolsa de látex ou condom, com aquecimento externo, onde as ninfas são postas para se alimentarem; a leitura é feita após 30, 45 e 60 dias.

Apesar das mencionadas facilidades quanto à criação ou obtenção de triatomíneos, seu transporte, aplicação e exame dos insetos, as quais sugeriam a maior conveniência de 
aplicação da "prova do barbeiro", sobretudo nas investigações epidemiológicas em grande escala, essa modalidade de diagnóstico inicialmente foi pouco utilizada. Os primeiros registros que demonstram a eficácia do método no diagnóstico etiológico da doença de Chagas foram feitos em 1933 por Torrealba, que encontrou 25\% de chagásicos entre os colonos de Guárico, na Venezuela (Torrealba, 1958). Dias (1940) foi o primeiro a estabelecer critérios para a utilização desse método, especialmente no que diz respeito ao triatomíneo a ser utilizado. Entretanto, o método só passou a ser empregado rotineiramente após sua padronização por Cerisola e colaboradores, em 1974.

O impacto do XD pode ser evidenciado se considerarmos sua aplicação há mais de noventa anos por pesquisadores e clínicos, trazendo grande contribuição ao diagnóstico e à pesquisa da doença de Chagas, no que tange ao potencial do método para o isolamento de cepas do parasito em humanos e outros mamíferos acometidos, assim como à avaliação da parasitemia e sua correlação com as condições clínicas da doença. Na década de 70 do século XX, o método passou a ser sistematicamente usado como ferramenta confiável para a seleção e avaliação de pacientes chagásicos que receberam quimioterapia específica (Schenone et al., 1970; Cançado et al., 1973; Cerisola et al., 1977).

O diagnóstico parasitológico da doença de Chagas apresenta maior complexidade na infecção crônica do que nos casos agudos. Embora tenham ocorrido aprimoramentos no diagnóstico parasitológico de fase crônica, a baixa sensibilidade dos exames indiretos ainda é um fator que limita sua aplicação no diagnóstico e controle pós-terapêutico. Dados da literatura indicam uma positividade do XD aplicado à fase crônica variando entre 9 e $87,5 \%$, dependendo da região estudada (revisto por Portela-Lindoso \& Shikanai-Yasuda, 2003). Estudos comparativos com ninfas de espécies diferentes foram realizados, visando a encontrar a melhor espécie a ser aplicada ao exame (Cerisola, Rohwedder \& Del Prado, 1971; Moreira \& Perlowagora-Szumlewicz, 1997). Foi sugerida a associação entre os métodos de XD e hemocultura para obtenção de uma sensibilidade máxima para a detecção do T. cruzi em pacientes na fase crônica da doença (Neal \& Miles, 1977).

Por outro lado, avanços no campo da biologia molecular permitiram o desenvolvimento de novas ferramentas, como a técnica da Reação em Cadeia da Polimerase (PCR), que, introduzida na década de 90 para a amplificação de ácidos nucléicos do T. cruzi em amostras de pacientes portadores da infecção crônica, vem sendo cada vez mais empregada no diagnóstico molecular da doença de Chagas (Avila et al., 1991; Britto et al., 1993, 1995; Wincker et al., 1994; Junqueira, Chiari \& Wincker, 1996). A maior sensibilidade da técnica, que possibilita verificar a presença de um parasito em $20 \mathrm{ml}$ de sangue, aponta para sua aplicação como método confirmatório no diagnóstico de pacientes com provas sorológicas duvidosas e como método auxiliar no controle pós-terapêutico da doença crônica, em comparação com as técnicas sorológicas e parasitológicas, embora exista preocupação quanto à especificidade da técnica quando realizada em serviços de rotina. Além disso, ensaios de PCR aplicados à doença de Chagas ainda não se encontram comercializados.

Nos dias atuais, o emprego do XD como rotina torna-se bastante restrito, devido à sua baixa sensibilidade e a limitações outras inerentes à técnica, tais como o tempo prolongado para o resultado final (alguns pesquisadores relatam um período de até 90 dias); a necessidade de estabelecer colônias de triatomíneos no laboratório; a morte dos insetos durante o período de teste e a rejeição do paciente à aplicação repetida do exame ao natural. A leitura do exame deve ser feita por técnico bem treinado, considerando-se a presença eventual de Trypanosoma rangeli e/ou Blastocrithidia triatomae no conteúdo intestinal dos triatomíneos (Cerisola et al., 1971). 
Ressalta-se, porém, o grande valor diagnóstico dos testes parasitológicos quando positivos. Durante a interpretação dos resultados, um XD positivo em indivíduo suspeito (quadro clínico, sorologia positiva e/ou antecedentes epidemiológicos) significa infecção pelo T. cruzi e pode confirmar uma etiologia chagásica; todavia, um resultado negativo não indica necessariamente ausência do parasito; nesse caso, deve-se proceder à repetição do exame. Porém, a despeito dos problemas que o XD in vivo ou in vitro possa apresentar, bem como da grande precisão que os métodos moleculares têm trazido ao diagnóstico da doença de Chagas, como enfatizam Opinel e Gachelin (2005), a contribuição de Brumpt para a definição e o diagnóstico, assim como para o conhecimento da biologia do parasito, ainda nos primórdios da descoberta da endemia, é de valor inestimável.

\section{Agradecimentos}

A Carlos R. Alves, pelas sugestões e idéias que contribuíram de certa forma para a elaboração do presente texto.

\section{REFERÊNCIAS}

AVILA, H. A. et al. Polymerase chain reaction amplification of Tiypanosoma cruzi kinetoplast minicircle DNA isolated from whole blood lysates: diagnosis of chronic Chagas disease. Molecular and Biochemical Parasitology, 48: 211-222, 1991.

BORGES-PEREIRA, J. et al. Parasitemia em pacientes chagásicos crônicos avaliada pelo índice de triatomíneos infectados no xenodiagnóstico. Revista da Sociedade Brasileira de Medicina Tropical, 22: 39-44, 1989.

BORGES-PEREIRA, J. et al. Xenodiagnóstico na doença de Chagas crônica. I. Sensibilidade de Panstrongylus megistus e Triatoma infestans. Revista da Sociedade Brasileira de Medicina Tropical, 29: 241-247, 1996.

BRITTO, C. et al. A simple protocol for the physical cleavage of Trypanosoma cruzi kinetoplast DNA present in blood samples and its use in polymerase chain reaction (PCR)-based diagnosis of chronic Chagas' disease. Memórias do Instituto Oswaldo Cruz, 88: 171-172, 1993.

BRITTO, C. et al. Polymerase chain reaction detection of Trypanosoma cruzi in human blood samples as a tool for diagnosis and treatment evaluation. Parasitology, 110: 241-247, 1995.

BRONFEN, E. et al. Isolamento de amostras do Trypanosoma cruzi por xenodiagnóstico e hemocultura de pacientes na fase crônica da doença de Chagas. Memórias do Instituto Oswaldo Cruz, 84: 237-240, 1989.

BRUMPT, E. O xenodiagnóstico: aplicação ao diagnóstico de algumas infecções parasitárias e em particular à tripanossomose de Chagas. Anais Paulistas de Medicina e Cirurgia, 3: 97-102, 1914.

CANÇADO, J. R. et al. Bases para avaliação do tratamento específico da doença de Chagas humana segundo a parasitemia. Revista da Sociedade Brasileira de Medicina Tropical, 7: 156-166, 1973.

CASTRO, C. N.; ALVES, M. T. \& MACEDO, V. O. Importância da repetição do xenodiagnóstico para avaliação da parasitemia na fase crônica da doença de Chagas. Revista da Sociedade Brasileira de Medicina Tropical, 16: 98-103, 1983.

CERISOLA, J. A.; ROHWEDDER, R. W. \& DEL PRADO, C. E. Rendimiento del xenodiagnóstico en la infección chagásica crónica humana utilizando ninfas de diferentes especies de triatominos. Boletín Chileno de Parasitología, 26: 57-58, 1971.

CERISOLA, J. A. et al. Blastocrithidia triatomae n. sp. found in Triatoma infestans from Argentina. The Fournal of Protozoology, 18: 503-506, 1971.

CERISOLA, J. A. et al. El Xenodiagnóstico. Normalización. Utilidad. Buenos Aires: Imprenta Instituto Nacional de Investigaciones Cardiológicas, 1974. 
CERISOLA, J. A. et al. Evaluación mediante xenodiagnóstico de la efectividad del nifurtimox en la infección chagásica crónica. Boletín Chileno de Parasitología, 32: 51-62, 1977.

COURA, J. R. et al. Evaluation of the xenodiagnosis of chronic Chagas patients infected ten years or over in an area where transmission has been interrupted: Iguatama and Pains, West Minas Gerais State, Brazil. Memórias do Instituto Oswaldo Cruz, 86: 395-398, 1991.

DIAS, E. Técnica do xenodiagnóstico na moléstia de Chagas. Memórias do Instituto Oswaldo Cruz, 35: 335-342, 1940.

FREITAS, J. L. P. et al. Estudo comparativo entre xenodiagnósticos praticados 'in vivo' e 'in vitro' em formas crônicas de moléstia de Chagas. O Hospital, 17: 101-110, 1955.

JUNQUEIRA, A. C. V.; CHIARI, E. \& WINCKER, P. Comparison of the polymerase chain reaction with two classical parasitological methods for the diagnosis of Chagas' disease in endemic region of NorthEastern Brazil. Transactions of the Royal Society of Tropical Medicine and Hygiene, 90: 129-132, 1996.

MOREIRA, C. J. C. \& PERLOWAGORA-SZUMLEWICZ, A. Attempts to improve xenodiagnosis: comparative test of sensitivity using Rhodnius neglectus, Panstrongylus megistus, Triatoma vitticeps, Triatoma infestans in endemic areas of Brazil. Memórias do Instituto Oswaldo Cruz, 92: 91-96, 1997.

NEAL, R. A. \& MILES, R. A. The sensitivity of culture methods to detect experimental infections of Trypanosoma cruzi and comparison with xenodiagnosis. Revista do Instituto de Medicina Tropical de São Paulo, 19: 170-176, 1977.

OPINEL, A. \& GACHELIN, G. Emile Brumpt's contribution to the characterization of parasitic diseases in Brazil, 1909-1914. Parassitologia, 47: 299-307, 2005.

PINEDA, P. J.; LUQUETTI, A. \& CASTRO, C. Comparação entre o xenodiagnóstico clássico e artificial na fase crônica da doença de Chagas. Revista da Sociedade Brasileira de Medicina Tropical, 31: 473-480, 1998.

PORTELA-LindosO, B. A. A. \& SHIKANAI-YASUDA, M. A. Doença de Chagas crônica: do xenodiagnóstico e hemocultura à reação em cadeia da polimerase. Revista de Saúde Pública, 37: 107115, 2003.

ROMAÑA, C. \& GIL, L. Xenodiagnóstico artificial. Anales del Instituto de Medicina Regional de Tucumán, 2: 57-60, 1947.

SCHENONE, H. Xenodiagnosis. Memórias do Instituto Oswaldo Cruz, 94: 289-294, 1999.

SCHENONE, H. et al. Valor do xenodiagnóstico na avaliação do tratamento da infecção crônica pelo Trypanosoma cruzi. Revista Goiana de Medicina, 16: 179-184, 1970.

SOUZA, H. B. W. T. et al. Estudo sobre o xenodiagnóstico 'in vitro'. II - Comparação com o xenodiagnóstico 'in vivo'. Revista do Hospital das Clínicas, 43: 165-167, 1988.

TORREALBA, J. F. Investigaciones sobre la Enfermedad de Chagas en San fuan de los Morros. Caracas: Imprenta Nacional, 1958.

WINCKER, P. et al. Use of simplified polymerase chain reaction procedure to detect Trypanosoma cruzi in blood samples from chronic chagasic patients in a rural endemic area. The American fournal of Tropical Medicine and Hygiene, 51: 771-777, 1994.

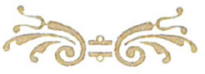




\title{
Xenodiagnóstico: reflexões sobre o desenvolvimento do método e sua importância nos estudos sobre a doença de Chagas
}

\author{
Liléia Diotaiuti \\ Laboratório de Triatomíneos e Epidemiologia da Doença de Chagas \\ Centro de Pesquisas René Rachou/Fiocruz
}

Émile Brumpt representa muito bem um grupo de naturalistas do final do século XIX e início do século XX, quando a descoberta do mundo dos micróbios já se consolidara por intermédio de inúmeros cientistas que, formados no Instituto Pasteur ou sob a influência deste, distribuíam-se pelo mundo como pesquisadores que se integrariam às mais importantes escolas de parasitologia, o que resultou em uma verdadeira explosão do número de parasitas descritos! Brumpt tinha 13 anos quando a teoria de Pasteur sobre a origem dos microrganismos foi aceita pela Academia Francesa de Ciência (1864). Naturalista licenciado em zoologia, botânica e geologia (1896), e posteriormente doutor em medicina (1906), tinha uma sólida formação que lhe possibilitou uma compreensão integral da natureza. Antes de vir para o Brasil, em 1903, havia participado de importantes excursões para a África e o Oriente, onde desenvolveu estudos sobre, entre outros, a malária e a doença do sono, incluindo o parasita e as moscas tse-tsé, e tripanossomas de peixes cuja transmissão ele determinou se dar por sanguessugas. Sua vivência como parasitologista já lhe havia ensinado as dificuldades para o diagnóstico de "moléstias parasitárias do sangue". Apesar de a reação de Guerreiro-Machado ter sido publicada em 1913, sua utilização era restrita, devido à complexidade na preparação dos reagentes e reprodutibilidade. Na verdade, o diagnóstico sorológico só avançou a partir das décadas de 60 e 80 do último século, e mesmo assim com muitas restrições. A demonstração do parasita no hospedeiro é prova contundente para que o médico decida sobre o encaminhamento clínico do paciente; tal informação tornou-se ainda mais importante a partir do advento, em 2005, do tratamento específico dos casos agudos ou pacientes na fase crônica ainda recente: "Nas tripanossomoses em particular, não só no homem como nos animais mais diversos, sabe-se como é difícil a existência dos tripanossomas, pelo exame direto".

O interesse pela doença descrita por Carlos Chagas era muito grande na ocasião. Convidado para organizar um curso de parasitologia na Faculdade de Medicina de São Paulo, Brumpt vem ao Brasil e passa a estudar parasitas brasileiros. A proposta do xenodiagnóstico vem do amadurecimento de uma seqüência de observações que inclui o estudo de peixes parasitados por um tripanossoma. Alimentando sanguessugas sobre serpentes e batráquios, os anelídeos também se infectaram com tripanossomas, comprovando a utilidade desse procedimento como método diagnóstico. Esses estudos não foram observações triviais, mas objeto do trabalho de Brumpt realizado em outros continentes e no Brasil no período de 1904 a 1914, quando o autor interrompeu suas pesquisas para uma "brusca partida para a guerra franco-alemã" e foi para Paris servir como médico em um hospital militar.

$\mathrm{Na}$ oportunidade do artigo aqui comentado, Brumpt aproveita para oferecer alguns detalhes não publicados sobre suas pesquisas acerca da sanguessuga Placobdella brasiliensis, espécie descrita pelo próprio autor em 1914, e hospedeiro do Trypanosoma leptodactyli. Ele observa que a sanguessuga completa sua alimentação em diversas espécies de rãs, crocodilos, serpentes, tartarugas, mas se recusa a se alimentar de alguns sapos ou peixes, evidenciando aspectos relacionados à suscetibilidade/refratariedade entre parasitas e hospedeiros. Descreve 
o número de repastos necessários para o animal tornar-se adulto, o procedimento de cópula, fecundação e postura de ovos, o desenvolvimento do T. brasili (parasita de serpentes) no estômago da sanguessuga, com produção de inúmeras formas metacíclicas que, segundo o autor, "não passam para a bainha da tromba, mesmo depois de vários meses, e é provável que a serpente se infeste ingerindo as sanguessugas parasitadas". Todos esses detalhes demonstram a capacidade de Brumpt para diferenciar morfologicamente espécies de tripanossomas hoje desconhecidas nas mais tradicionais escolas de parasitologia, que dependem de métodos moleculares para diferenciação das espécies cuja identificação depende da disponibilidade de seqüências gênicas conhecidas para serem usadas para a produção de marcadores específicos.

Nesse contexto, Brumpt, atento às novidades, experimenta com sucesso o diagnóstico de uma cobaia infectada com Trypanosoma cruzi, mas sem parasitemia patente, fazendo-a ser picada pelo que ele chamava de larvas de terceiro estádio de Triatoma (Conohinus) megista, hoje Panstrongylus megistus. A mesma experiência em crianças que ele define como "atacadas da moléstia de Chagas, antiga" teve resultado negativo, mas o autor já antecipa que "em casos recentes da moléstia de Chagas a infecção certamente se faria". Por suas experiências no desenvolvimento da técnica do xenodiagnóstico, Brumpt confirma que todos os estádios pósembrionários de triatomíneos se infectam com o T. cruzi, também determinando o tamanho do repasto nos diferentes estádios, quando postula que os triatomíneos ingerem sangue em quantidade de dez a quinhentas maior "que a quantidade (...) que se pode pôr entre lâmina e lamínula”, ou seja, 50 microlitros (Brener, 1961); ou mesmo medindo o repasto sangüíneo de ninfas de quinto estádio de Triatoma infestans e T. megista (Panstrongylus megistus). O artigo também antecipa que o $T$. cruzi cresce dentro dos triatomíneos livres da agressão de células do sistema imune, como se observa em cobaias inoculadas com o sangue de um doente e onde se evidencia a destruição de parasitas por leucócitos; realmente, até hoje não há comprovação de que o T. cruzi cause algum dano aos seus vetores (Billingsley \& Downe, 1983). Além disso, ainda na perspectiva da infecção dos vetores, segundo Brumpt a proposta de utilização do xenodiagnóstico para a identificação do parasitismo pelo T. cruzi é reforçada pela alta infecção experimental de Triatomas (T. infestans e T. megista) ou de Rhodnius ( $R$. prolixus), "estes maravilhosos hospedeiros vetores, em comparação com as glossinas e em outros tripanossomas de animais, que se infectam em proporção baixa".

Muito oportunamente, o xenodiagnóstico é proposto por Brumpt para ser utilizado em estudo sistemático e geográfico da moléstia de Chagas no homem e nos animais domésticos ou selvagens do Brasil. As alternativas da época eram o exame direto do sangue do paciente ao microscópio, entre lâmina e lamínula, ou a inoculação de cobaias, procedimentos complexos e quase inviáveis nas condições de campo, em transporte realizado a cavalo para remotas regiões do interior do Brasil. Mesmo que só esporadicamente recomendado como método de diagnóstico da infecção humana, o xenodiagnóstico segue como uma das formas mais fáceis de confirmação da infecção de reservatórios silvestres, permitindo o isolamento de amostras de T. cruzi para seu seguimento em meio de cultura (Bronfen et al., 1989) ou para caracterização direta da linhagem do parasita (Liarte, 2006).

Pela importância clínico-epidemiológica da utilização do xenodiagnóstico, muitos foram os seguidores de Brumpt no esforço de aprimoramento do método, com artigos e teses para determinação das espécies naturalmente mais suscetíveis ao T. cruzi (Szumlevicz, Muller \& Moreira, 1990), do número de triatomíneos, do estádio ideal de desenvolvimento e do tempo ideal para exame destes (Cerisola et al., 1974), com a busca de cepas de triatomíneos com maior suscetibilidade ao parasita (triatomíneos irradiados, seleção genética de cepas mais suscetíveis) 
(Phillips \& Bertram, 1967), e com a soma complementar de dois métodos de amplificação dos parasitas (xeno e cultivo do conteúdo intestinal dos triatomíneos em meio LIT) (Bronfen et al., 1989). Para Brumpt, a picada dos triatomíneos é indolor. Sabemos que não é exatamente assim, e também que a reação do hospedeiro à picada não é igual para todas as espécies e pode causar bastante incômodo ou reações graves do paciente (Pereira et al., 2006). Para o diagnóstico humano, o xenodiagnóstico caiu em desuso diante das novas possibilidades (MS/SVS, 2005); de fato, a imagem de quarenta triatomíneos sugando ao mesmo tempo os braços de uma pessoa é assustadora. O artigo de Brumpt, entretanto, deve ser apreciado como uma peça realmente rara da literatura científica, desenhado dentro dos rigores metodológicos da ciência, como uma verdadeira aula apresentada por um mestre da zoologia!

\section{REFERÊNCIAS}

BILLINGSLEY, P. F. \& DOWNE, A. E. R. Ultraestructural changes in posterior midgut cells associated with blood feeding in adult female Rhodnius prolixus Stal (Heteroptera: Reduviidae). Canadian fournal of Zoology, 61: 2.574-2.586, 1983.

BRENER, Z. Contribuição ao Estudo da Terapêutica Experimental da Doença de Chagas, 1961. Tese de Doutorado, Belo Horizonte: Universidade Federal de Minas Gerais.

BRONFEN, E. et al. Isolamento de amostras do Tiypanosoma cruzi por xenodiagnóstico e hemocultura de pacientes na fase crônica da doença de Chagas. Memórias do Instituto Oswaldo Cruz, 84(2): 237-240, 1989.

CERISOLA, J. A. et al. El Xenodiagnóstico. Buenos Aires: Instituto Nacional de la Enfermedad de Chagas Dr. Mario Fatala Chaben, 1974.

LIARTE, D. B. Desenvolvimento de uma PCR Multiplex Capaz de Detectar e Classificar Cepas de Trypanosoma cruzi em Amostras Clínicas e de Campo, 2006. Tese de Doutorado, Belo Horizonte: Centro de Pesquisas René Rachou, Fundação Oswaldo Cruz.

MINISTÉRIO DA SAÚDE. Secretaria de Vigilância em Saúde. Consenso brasileiro em doença de Chagas. Revista da Sociedade Brasileira de Medicina Tropical, 38, supl. III: 11-14, 2005.

PEREIRA, H. et al. Competitive displacement in Triatominae: the Triatoma infestans success. Trends in Parasitology, 22(11): 516-520, 2006.

PHILLIPS, N. R. \& BERTRAM, D. S. Laboratory studies of Trypanosoma cruzi infections. In: Rhodnius prolixus, larvae and adults. In: Triatoma infestans, T. protracta and T. maculata-adults. Fournal of Medical Entomology, 4(2):168-171, 1967.

SZUMLEWICZ, A. P.; MULLER, C. A. \& MOREIRA, C. J. C. Studies in search of a suitable experimental insect model for xenodiagnosis of hosts Chagas disease. 4. The reflection of parasite stock in the responsiveness of different vector species to chronic infection with different Tiypanosoma cruzi. Revista de Saúde Pública, 24(3): 165-177, 1990. 